\title{
Los estados atributivos y locativos: estudio semántico cognitivo de la caracterización en el español de Lima
}

\section{Attributive and locative states: a cognitive semantic study of characterization in Lima Spanish}

\author{
Verónica Lazo García \\ Universidad Nacional Mayor de San Marcos, Lima, Perú \\ veronica.lazo@unmsm.edu.pe \\ https://orcid.org/oooo-0oo2-3898-2594
}

\begin{abstract}
Resumen
Los estados atributivos relacionan entidades del mundo con propiedades. En el español, se expresan, en la sintaxis, como frases verbales constituidas por verbos copulativos o semicopulativos, como núcleos. y frases adjetivas, frases preposicionales, frases nominales y construcciones relativas como sus complementos. A nivel cognitivo, estas estructuras semántico-sintácticas cumplen una misma función: la caracterización de los objetos del mundo por parte de un conceptualizador. El objetivo de este trabajo es explicar este proceso cognitivo en el español describiendo sus estructuras semántico-sintácticas y su uso. Para ello, se ha empleado una muestra de 117 oraciones recogidas mediante una encuesta a 31 estudiantes universitarios. El análisis se realizó de acuerdo con los postulados de la semántica formal de Moreno Cabrera, 2003; Chafe, 1970; y de la semántica cognitiva de Talmy, 2000; Fillmore, 1985; y Langacker, 1999. Los resultados de la investigación muestran que, desde la sintaxis, la caracterización se expresa con mayor frecuencia con frases adjetivas, y en menor grado con frases preposicionales, participios y construcciones relativas. Desde el uso, la atribución se expresa de manera diferente en las mujeres y en los varones. Así, las mujeres utilizaron más atributos para caracterizar a las entidades y prestaron más atención al dominio conceptual del físico, como la forma y color de piel y cabello, la edad y la actitud. Los varones, en cambio, emplearon más la caracterización eventiva y atribuciones relacionadas con la postura de la entidad caracterizada.
\end{abstract}

Palabras clave: caracterización; estados; dominios conceptuales; ventana atencional; español de Lima

\begin{abstract}
Attributive states relate entities of the world to properties. In Spanish, they are expressed, in syntax, as projections of verb phrases structured by copulative or semicopulative verbs, as adjective nuclei and phrases, prepositional phrases, nominal phrases and relative constructions as their complements. At the cognitive level, these semantic-syntactic structures fulfill the same function: the characterization of world objects by a conceptualizer. The aim of this paper is to explain this cognitive process in Spanish by describing its semantic-syntactic structures and their use.
\end{abstract}


Los estados atributivos y locativos: estudio semántico cognitivo de la caracterización... Verónica Lazo García

For this purpose, a sample of 117 sentences collected through a survey of 31 university students was used. The analysis was carried out according to the postulates of the formal semantics of Moreno Cabrera, 2003; Chafe, 1970; and the cognitive semantics of Talmy, 2000; Fillmore, 1985; and Langacker, 1999. The results of the research show that, from syntax, characterization is most frequently expressed with adjective phrases, and to a lesser degree with prepositional phrases, participles and relative constructions. In terms of usage, attribution is expressed differently in women and men. Thus, women used more attributes to characterize the entities and paid more attention to the conceptual domain of the physical, such as the shape and color of skin and hair, age and attitude. Males, on the other hand, used more eventive characterization and attributions related to the posture of the characterized entity.

Keywords: characterization; states; conceptual domains; attentional windowing; Lima Spanish

\section{Resumo}

Os estados atributivos relacionam entidades do mundo com propriedades. Em espanhol, são expressos, em sintaxe, como projecções de frases verbais cujos núcleos são verbos copulativos ou semicopulativos, e os seus complementos, frases adjectivas, frases preposicionais, frases nominais e construções relativas. A nível cognitivo, estas estruturas semântico-sintácticas cumprem a mesma função: a caracterização dos objectos do mundo por um conceptualizador. O objectivo deste trabalho é explicar o processo cognitivo de caracterização em espanhol, descrevendo as suas estruturas semântico-sintácticas e a sua utilização. Para este fim, foi utilizada uma amostra de 117 frases recolhidas por meio de um inquérito a 31 estudantes universitários. A análise foi realizada de acordo com os postulados da semântica formal de Moreno Cabrera, 2003; Chafe, 1970; e a semântica cognitiva de Talmy, 2000; Fillmore, 1985; e Langacker, 1999. Os resultados da investigação mostram que, do ponto de vista da sintaxe, a caracterização é expressa mais frequentemente com frases adjectivas e, em menor medida, com frases preposicionais, particípios e construções relativas. Finalmente, a atribuição é expressa de forma diferente nas mulheres e nos homens. Assim, as mulheres utilizaram mais atributos para caracterizar entidades e prestaram mais atenção ao domínio conceptual da fisicalidade, tais como a forma e a cor da pele e do cabelo, a idade e a atitude. Os machos, por outro lado, fizeram mais uso da caracterização e das atribuições equilibradas relacionadas com a postura da entidade caracterizada.

Palavras-chave: caracterização; estados; domínios conceptuais; janela atencional; Lima Espanhol

Recibido: I8-05-202I

Aprobado: 15-06-202I

Publicado: I9-I2-202I

82 Lengua y Sociedad. Revista de Lingüística Teórica y Aplicada 
Los estados atributivos y locativos: estudio semántico cognitivo de la caracterización...

Verónica Lazo García

\section{Introducción}

La caracterización es un proceso cognitivo mediante el cual un individuo determina los atributos para una entidad (ya sea cosa, lugar, persona, animal o situación), con los cuales la distingue de las demás. La selección de las propiedades opera bajo los principios del sistema conceptual y sociocultural, es decir, se relaciona con las capacidades cognitivas del sujeto, como la percepción, la memoria, la atención, el lenguaje, la categorización, los modelos cognitivos, entre otros. Por ejemplo, una entidad denominada mujer puede ser caracterizada con los atributos atrevida, trabajadora, de contextura delgada, con el cabello recogido, que está leyendo. El hecho de que la entidad mujer reciba estos atributos se debe a que el hablante resalta estas propiedades de las demás, debido a que en su sistema conceptual y el sistema sociocultural del español la mujer cumple determinados roles y es aceptada sobre todo por la figura e imagen que proyecta.

Las estructuras semántico-sintácticas que relacionan entidades con propiedades son los estados atributivos, que se manifiestan en la sintaxis como predicados nominales o construcciones atributivas (Moreno, 2003; Chafe, 1970). En el español, los verbos ser-estar son los elementos lingüísticos que sirven de nexo entre las entidades que toman la forma de frases nominales y las propiedades, que se expresan en diferentes categorías sintácticas. El verbo ser indica una propiedad inherente permanente, como la mujer es gorda; mientras que el verbo estar muestra una propiedad inherente transitoria, como la mujer está gorda (Demonte, 1979). Asimismo, el hablante puede expresar su percepción/ opinión sobre tal relación; para ello, empleará verbos semicopulativos, como la mujer se ve gordita.

Si bien el estudio del significado de la oración toma como referencia las relaciones entre las entidades y las propiedades, consideramos que las herramientas teóricas de la gramática cognitiva ayudan a entender los aspectos cognitivos y culturales de la caracterización. De este modo, planteamos los siguientes objetivos de investigación: a) determinar los tipos de atribución más frecuentes en el español limeño, b) establecer las estructuras sintácticas que expresan las propiedades atribuidas, c) hallar qué propiedades son perfiladas para describir mujeres y niños, d) diferenciar la caracterización por parte de mujeres y varones. 
Los estados atributivos y locativos: estudio semántico cognitivo de la caracterización... Verónica Lazo García

\section{Marco conceptual, referencial o teórico}

\subsection{La semántica formal}

De acuerdo con la gramática generativa, las teorías del significado de la oración han intentado formalizar la estructura semántica del lenguaje. La semántica formal estudia el significado de manera lógica; de este modo, emplea notaciones que reducen el significado al contenido proposicional o descriptivo y lo explica por condiciones de verdad. No obstante, los significados son de diversos tipos, por lo cual no puede ser explicado por su contenido proposicional únicamente. Así, Lyons (1997) afirma que "gran parte del significado oracional, en muchas lenguas naturales, incluyendo el español, no es proposicional» (p. 231). Por ejemplo, el significado de la oración el perro está afuera, no se puede explicar solo por el contenido proposicional de cada uno de sus constituyentes, sino también por sus significados asociativos, como son los valores afectivos que una cultura o el hablante le asigna a la entidad perro, el uso individual, social o informal de la lengua, los múltiples sentidos del término perro, entre otros (Leech, 1977).

Según el principio de composicionalidad, el significado o el sentido denotativo de una expresión compuesta (sea una frase u oración) es una función de los significados de sus componentes. La función debe entenderse como una fórmula u operación que asigna un valor único a cada constituyente de la referida expresión y otorga a la proposición un valor de verdad. La semántica formal se ha desarrollado en dos direcciones, una más lingüística e interpretativa (Katz \& Fodor, 1963), y otra más lógica (gramática de Montague, 1974). Los primeros autores tratan los fenómenos semánticos desde la gramática transformacional. Consideran la semántica como la teoría de la capacidad de interpretar oraciones; para ello emplean los conceptos de diccionario y reglas de proyección. El diccionario asocia a cada unidad léxica un conjunto de significaciones, de acuerdo con categorías gramaticales, semánticas y diferenciadores. Las reglas de proyección, por su parte, se encuentran en la estructura profunda y determinan la interpretación de las oraciones aplicando la información del diccionario (Otaola, 2004).

\subsection{Semántica formal de Montague}

Richard Montague (1974) explica el contenido proposicional de las oraciones de manera matemática y de acuerdo con el principio de la composicionalidad; es decir, unifica el lenguaje natural con los lenguajes artificiales mediante mecanismos

84 Lengua y Sociedad. Revista de Lingüística Teórica y Aplicada 
Los estados atributivos y locativos: estudio semántico cognitivo de la caracterización...

Verónica Lazo García

formales y reconoce el paralelismo entre la estructura sintáctica y la estructura semántica, tanto en las categorías como en las reglas, las cuales son la base de su gramática. Sin embargo, no empleó reglas transformacionales (como sílo hicieron Katz y Fodor) debido a que su análisis semántico correspondía a la estructura superficial.

En la teoría de Montague, el significado de la oración es lógico y denotativo y se relaciona con los sucesos del mundo real o imaginario. La verdad, por tanto, no es absoluta, sino relativa a una representación abstracta de una parte de ese mundo real o imaginario, conocido como modelo, el cual este está formado por elementos, relaciones y propiedades (Moreno, 2003).

\subsection{La caracterización de entidades}

La operación semántica de caracterización origina varios mecanismos sintácticos. Moreno (2003) reconoce tres subtipos: espacial, cualitativa y situacional, que se muestran en 1, 2 y 3 , donde la entidad niña ha sido caracterizada de las tres maneras.

(1) La niña está en el columpio.

(2) La niña está enojada.

(3) La niña molesta a su hermano.

En primer lugar, la caracterización espacial de (1) da cuenta de la forma como los individuos o entidades mantienen relaciones con los lugares en los que se encuentran. En segundo lugar, la caracterización cualitativa de (2) consiste en que las entidades tienen determinadas propiedades. En tercer lugar, la caracterización situacional o de ocupación (3) consiste en la determinación del papel que desempeña la entidad en un suceso o escena, en este caso es el agente del predicado molestar.

\subsection{Sucesos: estados, procesos y acciones}

Los sucesos son categorías lingüístico-cognitivas que describen diversos tipos de situaciones como estados, procesos y acciones (Moreno, 2003). Los estados relacionan entidades con propiedades o lugares, como en 1 y 2. Los procesos se definen como relaciones de transición entre estados; es decir, hay un proceso cuando una entidad, de estar en un estado pasa a estar en otro estado, como en 
Los estados atributivos y locativos: estudio semántico cognitivo de la caracterización... Verónica Lazo García

la niña se enojó, que es un proceso que indica que la niña en un primer momento no estaba enojada y luego pasó a estar enojada. Finalmente, las acciones son relaciones entre procesos y entidades, por ejemplo, el niño enojó a la niña, donde la entidad el niño origina o controla el proceso que se entiende como una transición de estado atributivo que padece la niña. Los tres tipos de sucesos se formalizan de la siguiente manera:

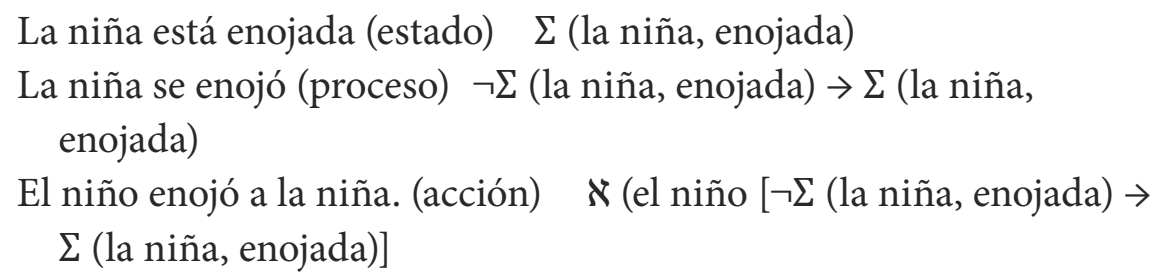

\subsubsection{Los estados atributivos}

Los estados pueden ser locativos y atributivos. Los primeros relacionan una entidad con un lugar. En cambio, los estados atributivos no son relaciones entre entidades, sino especificaciones de propiedades de entidades (Moreno, 2003) y, por ello, denotan un conjunto de entidades, las que tienen una propiedad determinada. Así, por ejemplo, el significado de la oración Juan es cuidadoso indica que Juan es una entidad que tiene la propiedad de ser cuidadoso. Esta propiedad es una función que denota un conjunto de entidades que tienen tal propiedad. En la semántica formal, esta relación se representa de manera relacional y operacional:

Notación relacional: $\sum$ (Juan, cuidadoso)

Donde $\Sigma=$ tener la propiedad de

Notación operacional: CuIDADoso (Juan)

Ambas notaciones se expresan mediante la oración Juan es cuidadoso, la cual puede ser verdadera o falsa. Para indicar que un verbo puede o no ser especificado como un estado Chafe (1970) propone utilizar la regla:

$$
\mathrm{V} \rightarrow \text { estado }
$$

Sin embargo, según Moreno (2003), el tipo de verbo no determina el tipo de suceso como señala Chafe. Por ejemplo, el verbo estar puede denotar estado, como en él está triste, o resultado, como en el está muerto.

86 Lengua y Sociedad. Revista de Lingüística Teórica y Aplicada 
Los estados atributivos y locativos: estudio semántico cognitivo de la caracterización...

Verónica Lazo García

\subsubsection{Tipos de atribución}

Según el tipo de caracterización, la atribución puede ser inherente o adherente. En la caracterización inherente, las propiedades son propias a las entidades, como se muestra en Juan es flaco. La caracterización adherente, en cambio, se refiere a las propiedades que puede alcanzar la entidad, como se aprecia en Juan es presidente.

Según la temporalidad, se pueden emplear las mismas propiedades para caracterizar las entidades, pero unas veces pueden entenderse como propiedades permanentes y otras, como transitorias. Este matiz semántico se establece por el uso de los verbos ser y estar. En la oración Juan es flaco el atributo es inherente permanente por el verbo ser. En Juan está flaco, también se emplea la propiedad inherente de la entidad, el adjetivo flaco, pero esta vez se trata de una característica transitoria, expresada por el verbo estar. En Juan es presidente y Juan está de presidente la propiedad no es física (inherente), sino se trata de una propiedad adherente, la cual puede ser permanente o transitoria.

Según la relación entre una o dos entidades, pueden encontrarse dos tipos de atribuciones: monovalentes y polivalentes. En la atribución monovalente, la propiedad es atribuida a una sola entidad, como en Juan es flaco. Por su parte, es polivalente cuando se relacionan dos entidades mediante una atribución, por ejemplo, en Juan es amigo de Pedro, las dos entidades se vinculan por la propiedad de la amistad.

\subsection{Aspectos semánticos de ser y estar}

Según Demonte (1979), en español los verbos ser/ estar no se generan en la estructura subyacente porque su aparición es predecible. La cópula no está presente en la estructura profunda, aunque la rama V sí lo está. Ahora bien, son muchos los significados que pueden expresarse con estos verbos, pero su contribución al significado de la oración está determinada completamente por las piezas que ellos relacionan. Por ejemplo, en la oración 5, [ser+ FN] indica ser miembro de una clase; mientras que en la oración 6, [estar + FADJ] refiere al resultado de un proceso: enfermarse.

(4) Juliana es periodista.

(5) Ella está enferma.

Como se puede advertir ser cumple principalmente la función de identificación de una entidad a partir de la propiedad que se refiere al individuo en su totalidad. 
Los estados atributivos y locativos: estudio semántico cognitivo de la caracterización... Verónica Lazo García

Se trata de propiedades más estables o permanentes. Además, también se aprecia significados de existencia (7) y posesión (8).

(6) La reunión será a las diez.

(7) La casa es de José.

En cambio, el verbo estar funciona para relacionar entidades con un lugar, como se muestra en (9), es decir, su función es de localización, no es identificadora.

(8) Juan estál*es en Lima.

Hay propiedades que aceptan una atribución permanente y transitoria. Por ejemplo:

(9) Juan es/ está nervioso.

(10) Juana es / está sola (en el español andino)

\subsection{Las construcciones relativas}

La operación de caracterización individual eventiva está determinada por principios semánticos universales. Uno de estos principios es la determinación, por la cual se restringe el dominio denotativo de una entidad. De esta manera, entre adjetivos, participios y proposiciones subordinadas relativas, existe un continuum de caracterización, donde las relativas son más caracterizadoras, esto es, precisan más el significado del nombre (Moreno, 1998).

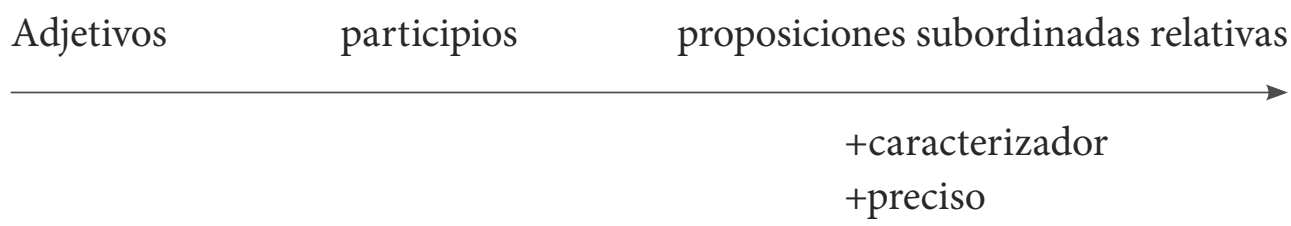

En las oraciones relativas, existe una operación cognitiva, la caracterización eventiva, por la cual se caracteriza a una entidad por su papel en un evento.

El verbo, como elemento que nos señala la propiedad esencial del evento es, pues, un objetivo principal en la expresión de la caracterización individual eventiva. [...] El otro elemento esencial de esta operación es la función que desempeña en el evento caracterizador la entidad caracterizada por él. Esta

88 Lengua y Sociedad. Revista de Lingüística Teórica y Aplicada 
Los estados atributivos y locativos: estudio semántico cognitivo de la caracterización...

Verónica Lazo García

función será una de las canónicas en un evento: agente, paciente, benefactivo, instrumental, locativo, temporal y otras (Moreno, 1998, p. 80).

Los sucesos pueden caracterizar a las entidades. Por ejemplo, en el enunciado Ella corre, la entidad referida por ella es caracterizada como agente de corre, o en el enunciado la niña compró un globo, la entidad designada por globo, queda caracterizada como paciente del verbo compró. Según el papel semántico que cumpla la entidad en el suceso, tendrá diferentes grados de caracterización y «cuanto mayor sea tal grado de caracterización de un participante por una acción, proceso o estado, menos marcada y más fácil será la subordinación adjetiva que se construye sobre la base de ese participante» (Ibíd., p. 81).

\subsection{Los dominios cognitivos}

La organización en dominios cognitivos se opone a los análisis en los que el significado de una expresión se reduce a un conjunto de rasgos semánticos (en la mayoría de los casos, abstractos, idealizados y de carácter universal). Un dominio cognitivo es una conceptualización integrada que presupone otros conceptos, no una suma restrictiva de rasgos, por ello, «toda expresión pertenece a un contexto en el que naturalmente ocurre y que constituye su dominio o marco» (Maldonado, 2012, p. 220). Por ejemplo, el significado de hipotenusa se encuentra dentro del dominio conceptual de triángulo (Langacker, 1999); martes se relaciona con el dominio semana. De este modo, la caracterización es posible porque las propiedades se hallan organizadas de acuerdo con marcos conceptuales, es decir, al significado enciclopédico de los hablantes.

\subsection{Semántica de marcos}

Según la semántica de marcos (Fillmore, 1985), el estudio del significado no solo se ajusta a condiciones de verdad. Se requiere aceptar la relación entre semántica, pragmática y la función en el discurso. Los marcos son estructuras de conocimiento enciclopédico; de este modo, el significado de una palabra solo puede ser entendido en referencia a la experiencia, creencias y prácticas sociales. El marco es organizador de la experiencia, es una herramienta para la comprensión y la descripción del significado léxico y gramatical: «un frame representa la organización particular de conocimiento que es el requisito de nuestra habilidad para comprender el significado que asociamos a las palabras» (Fillmore, 1985, p. 224). 
Los estados atributivos y locativos: estudio semántico cognitivo de la caracterización... Verónica Lazo García

\subsection{Ventana atencional y perfilamiento}

Una ventana es una frase explícita que refiere a una escena o marco que queda en segundo plano. En el contexto adecuado, el destinatario infiere el resto de la escena (Talmy, 20oo). Un mismo referente como la mujer de la figura 1 puede ser objeto de una ventana de maneras diferentes. Para describir el proceso de atención, es necesario comprender que los usuarios de la lengua conciben ciertos elementos como pertenecientes al núcleo central de la identificación de un objeto, mientras que otros los conceptualizan como periféricos y no son parte del marco.

El perfilamiento es la referencia dentro de una conceptualización, el nombre tía perfila una relación de parentesco dentro del nombre familia. Al perfilar algún rasgo o elemento del marco, se deja de perfilar otros, llamados figura secundaria. El perfilamiento ha sido visto como un efecto visual, es decir, el perfilamiento de una expresión es el foco de atención dentro de su alcance (Langacker, 1999).

En la figura 1, presentamos la imagen 1 del cuestionario. Se pidió a los colaboradores que respondan ¿cómo es la mujer de la imagen?, y ¿qué está haciendo? El $61.9 \%$ de atributos empleados corresponden al dominio del físico; mientras que el $7.14 \%$ se refieren a la edad. Al respecto de lo físico, mujeres y varones emplearon los adjetivos gorda, gordita, obesa, blanca, de tez clara, guapa, bonita, vestida con ropa deportiva. Solo las mujeres la caracterizaron por la forma del cabello: de pelo corto, de cabello castaño. El rasgo del cabello para identificar la entidad solo es atendida o puesta en perfilamiento por las mujeres, debido a sus propias características físicas y sociales compartidas.

Figura 1. Imagen 1 del cuestionario

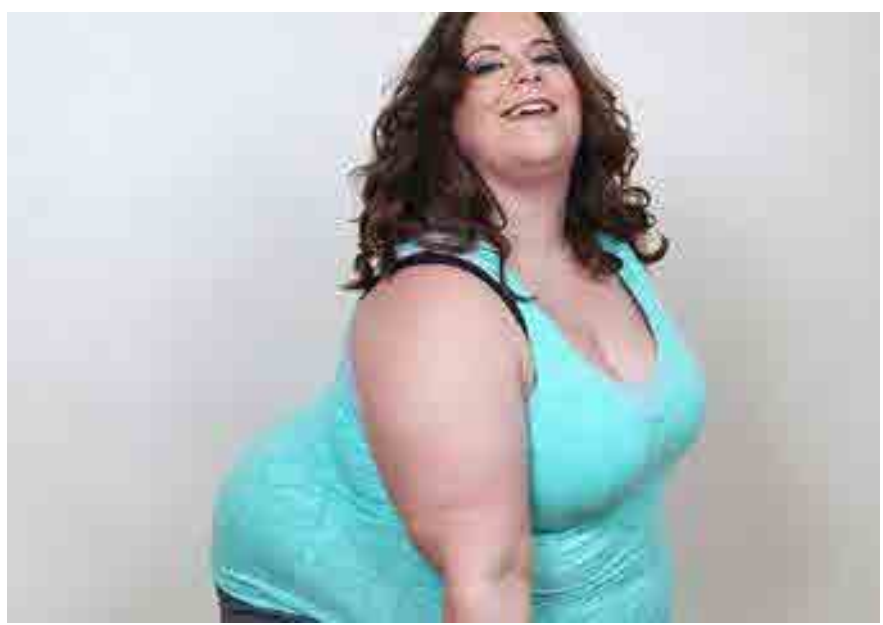


Los estados atributivos y locativos: estudio semántico cognitivo de la caracterización...

Verónica Lazo García

\section{Metodología}

La investigación es de tipo descriptiva, debido a que detallamos la estructura semántico-sintáctica de las construcciones atributivas, referidas a cinco objetos del mundo. Asimismo, analizamos el proceso cognitivo de la caracterización, como resultado del perfilamiento de ciertas propiedades de acuerdo al género en el contexto sociocultural del español de Lima.

La muestra está constituida por 117 oraciones, 64 de mujeres y 53 de varones (estudiantes de la Universidad San Marcos). Se recogió la muestra mediante un formulario de Google (marzo, 2021). Estas oraciones corresponden a la caracterización de cinco imágenes del cuestionario. La tabla 1 resume la cantidad de oraciones por imagen, considerando el género de los colaboradores, quienes fueron respectivamente 17 mujeres y 14 varones.

Tabla 1. Oraciones que constituyen la muestra de la investigación según la imagen y género de los colaboradores

\begin{tabular}{|l|l|l|l|l}
\hline $\begin{array}{l}\text { Número de } \\
\text { imagen }\end{array}$ & $\begin{array}{l}\text { Objeto del } \\
\text { mundo } \\
\text { representado }\end{array}$ & mujeres & Varones & Total \\
\hline 1 & Mujer & 13 & 14 & 27 \\
\hline 2 & Mujer & 10 & 10 & 20 \\
\hline 3 & Mujer & 14 & 10 & 24 \\
\hline 4 & Niños & 17 & 13 & 30 \\
\hline 5 & Niños & 10 & 6 & 16 \\
\hline Total & & 64 & 53 & 117 \\
\hline & & & & \\
\hline
\end{tabular}

El cuestionario fue compartido vía Formulario de Google a los colaboradores de la investigación. Contenía 7 imágenes y oraciones para completar. En la primera parte, se les pidió que describieran a las personas representadas en las imágenes, respondiendo determinadas preguntas. Se les preguntó qué hacían las entidades para corroborar si construían oraciones relativas (ver anexo 1). Por cada imagen, se obtuvieron enunciados bajo la forma de oraciones o de frases que caracterizaban a las entidades. Solo se seleccionó aquellas que contenían estados y no acciones.

En el análisis formal, se determinó las clases de propiedades inherentes o adherentes, permanentes o transitorias; las estructuras sintácticas con las que se expresan y la formalización de las propiedades, ya que no siempre tenían una 
Los estados atributivos y locativos: estudio semántico cognitivo de la caracterización... Verónica Lazo García

representación oracional. De otra parte, en el análisis cognitivo, se clasificó las atribuciones de acuerdo con la categorización en dominios cognitivos y cómo ciertas propiedades se perfilaron o se atendieron más según el género. Se anotó la frecuencia de las propiedades dentro de determinados dominios por cada imagen y por género.

Tabla 2. Ejemplo de ficha de análisis

\begin{tabular}{l|l|l|l|l|l}
\hline \multicolumn{5}{c}{ Figura 1/ Dominio A: Físico- contextura } \\
\hline $\begin{array}{l}\text { CLASE DE } \\
\text { PROPIEDAD }\end{array}$ & $\begin{array}{l}\text { Estructura } \\
\text { sintáctica }\end{array}$ & $\begin{array}{l}\text { Formalización de } \\
\text { la atribución }\end{array}$ & MUJERES & VARONES & TOTAL \\
\hline \multirow{2}{*}{$\begin{array}{l}\text { Inherente } \\
\text { permanente }\end{array}$} & \multirow{2}{*}{ SER+FADJ } & $\sum$ (mujer, gorda) & 5 & 3 & 8 \\
\hline & & $\sum$ (mujer, gordita) & 1 & 0 & 1 \\
\hline & & $\sum$ (mujer, obesa) & 2 & 3 & 5 \\
\hline Total & & 10 & 9 & 19 \\
\hline
\end{tabular}

\section{Análisis}

Las estructuras sintácticas de las 117 entradas del corpus expresan atribuciones de tipo monovalente y polivalente. Las primeras relacionan las entidades de las imágenes del cuestionario con propiedades que se estructuran en diversos dominios cognitivos, como la mujer es gorda, $\sum$ (mujer, gorda). Las segundas relacionan las propiedades con otra entidad, como peso o cabello, como la mujer subida de peso, $\sum^{\text {subida }}$ (mujer, de peso). En el plano semántico, la recurrencia de propiedades inherentes fue mayor que las adherentes, y el perfilamiento de propiedades resultó mayor al rol semántico de la entidad en un evento, en consecuencia, en el plano sintáctico, el uso de frases adjetivas fue mayor que las construcciones relativas.

\subsection{Propiedades permanentes}

Las propiedades permanentes son cualidades propias de las entidades dentro de un determinado modelo, marco o frame. Se aprecia que el dominio de lo físico constituye una propiedad permanente; se expresa en propiedades como la contextura, el color de piel y de cabello, el tamaño, la edad y la belleza. Estas propiedades aparecen en la sintaxis con la estructura $\{$ ser+Fadj\}, como en es gorda, corroborando lo dicho por Demonte (1979) sobre la función identificadora del verbo ser $\mathrm{y}$ adjetivos calificativos. Aparecen también estructuras como $\{$ ser + participio\}, 
Los estados atributivos y locativos: estudio semántico cognitivo de la caracterización...

como mujer decidida, $\{$ ser+Fprep $\}$, como mujer de contextura gruesa y $\{$ tener+FN $\}$, como tiene el cabello amarrado.

\subsection{Propiedades transitorias}

Estas propiedades definen a la entidad o pueden ser alcanzadas por un momento. La contextura, postura e imagen se expresan con la estructura \{estar + participio\}, como estar subida de peso; la localización, con la estructura \{estar+Fprep\}, como está en la cama saltarina; y la actitud, con la estructura \{estar+FAdj\}, como está alegre. Muchos de los estados son resultado de procesos o acciones, expresados con los verbos vestir, arreglar, cansar, echar, acostar, parar. Las frases la niña de polo morado y la niña con dos colitas corresponden a los estados la niña vestida de polo morado ( $\sum^{\text {Vestida }}$ (niña, de polo morado) y la niña peinada con dos colitas ( $\sum^{\text {PeInada }}$ (niña, con dos colitas). A continuación, en la tabla 3 presentamos aquellas propiedades que podían ser permanentes y transitorias.

Tabla 3. Comparación de propiedades que podían ser permanentes y transitorias

\begin{tabular}{|c|c|c|c|c|}
\hline \multirow{2}{*}{$\begin{array}{l}\text { Dominio } \\
\text { conceptual }\end{array}$} & \multicolumn{4}{|c|}{ Estructura sintactica } \\
\hline & Verbo & \multicolumn{3}{|l|}{ Complemento } \\
\hline \multirow[t]{2}{*}{ Físico } & $\begin{array}{l}\text { SER } \\
\text { (permanente) }\end{array}$ & $\begin{array}{l}\text { FA } \\
\sum \text { (mujer, gorda) }\end{array}$ & \multicolumn{2}{|c|}{$\begin{array}{l}\text { FP }(\text { de }) \\
\sum^{\text {en }}(\text { mujer, contextura gruesa } \\
\text { robusta) }\end{array}$} \\
\hline & $\begin{array}{l}\text { ESTAR } \\
\text { (transitoria) }\end{array}$ & \multicolumn{3}{|c|}{$\begin{array}{l}\text { PARTCIPIO } \\
\sum^{\text {subida }} \text { (mujer, de peso) }\end{array}$} \\
\hline \multirow{2}{*}{ Localización } & $\begin{array}{l}\text { SER } \\
\text { (transitoria) }\end{array}$ & \multicolumn{3}{|c|}{$\begin{array}{l}\text { FP } \\
\sum^{\text {en }} \text { (niño, columpio/ trampolín/ esquina) }\end{array}$} \\
\hline & $\begin{array}{l}\text { ESTAR } \\
\text { (transitoria) }\end{array}$ & \multicolumn{3}{|c|}{$\begin{array}{l}\text { FP } \\
\sum^{\text {en }}(\text { niño, cama saltarina })\end{array}$} \\
\hline \multirow{3}{*}{ Imagen } & $\begin{array}{l}\text { Tener } \\
\text { (transitoria) }\end{array}$ & \multicolumn{3}{|c|}{$\begin{array}{l}\text { FN } \\
\sum \text { amarrado, desordenado, recogido (cabello, niña) }\end{array}$} \\
\hline & $\begin{array}{l}\text { Ser } \\
\text { (permanente) }\end{array}$ & $\begin{array}{l}\text { FA } \\
\sum \text { (mujer, } \\
\text { atlética) }\end{array}$ & $\begin{array}{l}\text { FP } \\
\sum^{\text {en }} \text { (niña, gran } \\
\text { sonrisa) }\end{array}$ & $\begin{array}{l}\text { FN } \\
\sum \text { (mujer, } \\
\text { deportista) }\end{array}$ \\
\hline & $\begin{array}{l}\text { Estar } \\
\text { (transitoria) }\end{array}$ & \multicolumn{3}{|c|}{$\begin{array}{l}\text { PARTICIPIO } \\
\sum^{\text {vestida }} \text { (mujer, con ropa deportiva) }\end{array}$} \\
\hline
\end{tabular}


Los estados atributivos y locativos: estudio semántico cognitivo de la caracterización... Verónica Lazo García

\begin{tabular}{|c|c|c|c|c|}
\hline \multirow{2}{*}{$\begin{array}{l}\text { Dominio } \\
\text { conceptual }\end{array}$} & \multicolumn{4}{|c|}{ Estructura sintactica } \\
\hline & \multirow{2}{*}{$\begin{array}{l}\text { Verbo } \\
\text { Ser } \\
\text { (permanente) }\end{array}$} & \multicolumn{3}{|l|}{ Complemento } \\
\hline \multirow[t]{3}{*}{ Actitud } & & $\begin{array}{l}\text { FA } \\
\sum \text { (mujer, feliz, } \\
\text { sonriente, } \\
\text { alegre) }\end{array}$ & $\begin{array}{l}\text { FP } \\
\sum \text { en (mujer, } \\
\text { semblante } \\
\text { alegre) }\end{array}$ & $\begin{array}{l}\text { PARTICIPIO } \\
\sum \text { (mujer, } \\
\text { decidida) }\end{array}$ \\
\hline & $\begin{array}{l}\text { Tener } \\
\text { (transitoria) }\end{array}$ & \multicolumn{3}{|c|}{$\sum^{\mathrm{EN}}($ ceño fruncido, niña) } \\
\hline & $\begin{array}{l}\text { Estar } \\
\text { (transitoria) }\end{array}$ & \multicolumn{3}{|c|}{$\begin{array}{l}\text { FA } \\
\sum \text { (mujer, alegre, feliz) }\end{array}$} \\
\hline
\end{tabular}

\subsection{Verbos semicopulativos}

También se aprecia el uso de verbos semicopulativos. En primer, lugar el uso de ver no predica la percepción visual de la entidad mujer. Según la Academia, este verbo indica resultado, que se puede ver a simple vista y en ese sentido expresa manifestación (RAE, 2010). El verbo parecer indica menos certeza del estado u opinión. «Las propiedades o los estados que el atributo denota pueden manifestarse en su apariencia, es decir, en cuanto que son percibidos externamente» (RAE, 2010, p. 726). En la tabla 4, se muestran los verbos pronominales encontrarse, hallarse, mostrarse, presentarse, revelarse, verse, así como aparecer y lucir, que expresan este aspecto.

Tabla 4. Propiedades que expresan manifestación o juicio

\begin{tabular}{|c|c|c|}
\hline \multirow{2}{*}{$\begin{array}{l}\text { Dominio } \\
\text { conceptual }\end{array}$} & \multicolumn{2}{|c|}{ Estructura sintáctica } \\
\hline & Verbo & Complemento \\
\hline Contextura & ver & $\begin{array}{l}\text { PARTCIPIO } \\
\sum \text { (mujer, llenita) }\end{array}$ \\
\hline Edad & verse & $\begin{array}{l}\text { FA } \\
\sum \text { (mujer, madura) }\end{array}$ \\
\hline Imagen & andar, ir, verse & $\begin{array}{l}\text { PARTICIPIO } \\
\sum^{\text {vestida de azul (mujer, andar) }}\end{array}$ \\
\hline Actitud & $\begin{array}{l}\text { posar, } \\
\text { encontrarse, } \\
\text { parecer, verse }\end{array}$ & $\begin{array}{l}\text { FA } \\
\sum \text { (mujer, feliz,) }\end{array}$ \\
\hline
\end{tabular}

94 Lengua y Sociedad. Revista de Lingüística Teórica y Aplicada 
Los estados atributivos y locativos: estudio semántico cognitivo de la caracterización...

Verónica Lazo García

\subsection{Dominios cognitivos}

$\mathrm{Al}$ caracterizar a las entidades de las imágenes, los colaboradores emplearon propiedades que se agrupan dentro de cuatro dominios cognitivos: a) postura-lugar, b) actitud, c) acción y d) concreto visual. Este último dominio alberga propiedades de contextura, color de piel, de cabello, edad, ropa, imagen y evaluación de la belleza.

En la caracterización de las personas representadas en las imágenes, el uso de las propiedades no fue proporcional. Así, en las imágenes predominan propiedades referidas a lo concreto visual. En la caracterización de niños, se considera el lugar donde están, pero no se recurre a esta atribución al caracterizar a las mujeres. Por tanto, la caracterización surge a partir de una evaluación de la función social de la entidad representada en las imágenes. La tabla 5 muestra la frecuencia de uso de las atribuciones para cada imagen.

Tabla 5. Frecuencia de uso de dominios conceptuales por imagen

\begin{tabular}{l|l|l}
\hline Objeto del mundo & Dominio conceptual & Frecuencia \\
\hline \multirow{4}{*}{ Mujer (figura 1) } & $\begin{array}{l}\text { Concreto-visual } \\
\text { (físico, belleza, edad, imagen) }\end{array}$ & $83.34 \%$ \\
\hline & Actitud & $16.6 \%$ \\
\hline & $\begin{array}{l}\text { Concreto-físico } \\
\text { (imagen, físico, edad) }\end{array}$ & $54.64 \%$ \\
\hline & Actitud & $36.36 \%$ \\
\hline & Acciones & $9 \%$ \\
\hline \multirow{3}{*}{ Mujer (figura 3) } & $\begin{array}{l}\text { Concreto-físico } \\
\text { (físico, edad, imagen) }\end{array}$ & $39.92 \%$ \\
\hline & Actitud & $28.5 \%$ \\
\hline & Postura & $20 \%$ \\
\hline & Acciones & $11.4 \%$ \\
\hline \multirow{2}{*}{ Niños (figura 4) } & Lugar & $60.6 \%$ \\
\hline & Acciones & $18.1 \%$ \\
\hline & $\begin{array}{l}\text { Concreto-visual } \\
\text { (imagen, físico) }\end{array}$ & $12 \%$ \\
\hline & Postura & $9 \%$ \\
\hline
\end{tabular}


Los estados atributivos y locativos: estudio semántico cognitivo de la caracterización... Verónica Lazo García

\begin{tabular}{|l|l|l}
\hline Objeto del mundo & Dominio conceptual & Frecuencia \\
\hline \multirow{2}{*}{ Niños (figura 5) } & $\begin{array}{l}\text { Concreto-visual } \\
\text { (imagen, físico, edad) }\end{array}$ & $67.5 \%$ \\
\hline & Actitud & $23.5 \%$ \\
\hline & Acciones & $5.8 \%$ \\
\hline & Lugar & $2.9 \%$ \\
\hline
\end{tabular}

\subsection{El dominio concreto visual}

Este dominio abarca las propiedades inherentes del físico, la edad, y también la imagen que proyecta la entidad y la evaluación de su belleza.

\section{A. El físico}

Se consideran dentro de este subdominio la contextura, el color de piel y el color de cabello. Estas dos últimas propiedades son empleadas en su mayoría por las mujeres.

1. La contextura. La tabla 6 muestra que los niños (imágenes 4 y 5) no son caracterizados con esta atribución. Los hombres y mujeres emplean propiedades de contextura de la misma forma. La estructura sintáctica ser + FAdj. Es la más frecuente ( $71.42 \%)$. El uso de este mismo verbo con preposiciones es bajo; así, con la preposición con alcanza un 14.28 \% y con el nexo de, $7.14 \%$. 
Los estados atributivos y locativos: estudio semántico cognitivo de la caracterización... Verónica Lazo García

Tabla 6. Frecuencia de uso de estructuras semántico-sintácticas de propiedades relacionadas con la contextura

\begin{tabular}{|c|c|c|c|c|c|}
\hline Imagen & $\begin{array}{l}\text { Estructura } \\
\text { sintáctica }\end{array}$ & Formalización & Mujeres & Varones & Total \\
\hline \multirow{6}{*}{1} & \multirow{3}{*}{ SER+FADJ } & $\sum$ (mujer, gorda) & 5 & 3 & 8 \\
\hline & & $\sum$ (mujer, gordita) & 1 & 0 & 1 \\
\hline & & $\sum$ (mujer, obesa) & 2 & 3 & 5 \\
\hline & $\begin{array}{l}\text { SER + FPREP } \\
(\mathrm{DE})\end{array}$ & $\begin{array}{l}\sum^{\mathrm{DE}}(\text { mujer, } \\
\text { contextura gruesa/ } \\
\text { robusta })\end{array}$ & 1 & 1 & 2 \\
\hline & \multirow{2}{*}{$\begin{array}{l}\text { SER + FPREP } \\
(\mathrm{CON})\end{array}$} & $\begin{array}{l}\sum^{\text {con }}(\text { mujer, } \\
\text { obesidad })\end{array}$ & 1 & 0 & 1 \\
\hline & & $\begin{array}{l}\sum^{\text {con }} \text { (mujer, } \\
\text { sobrepeso) }\end{array}$ & 0 & 2 & 2 \\
\hline \multirow{4}{*}{2} & SER+FADJ & $\sum$ (mujer, gorda) & 0 & 1 & 1 \\
\hline & $\begin{array}{l}\text { VER }+ \\
\text { PARTICIPIO }\end{array}$ & $\sum$ (mujer, llenita) & 1 & 0 & 1 \\
\hline & $\begin{array}{l}\text { ESTAR + FADJ } \\
\text { PARTICIPIO }\end{array}$ & $\begin{array}{l}\sum \text { (mujer, subida de } \\
\text { peso) }\end{array}$ & 0 & 1 & 1 \\
\hline & $\begin{array}{l}\text { SER + FPREP } \\
(\mathrm{CON})\end{array}$ & $\begin{array}{l}\sum^{\text {con }} \text { (mujer, } \\
\text { sobrepeso) }\end{array}$ & 0 & 1 & 1 \\
\hline 3 & SER+FADJ & $\begin{array}{l}\sum \text { (mujer, delgada/ } \\
\text { esbelta) }\end{array}$ & 2 & 3 & 5 \\
\hline \multicolumn{3}{|l|}{ TOTAL } & 13 & 15 & 28 \\
\hline
\end{tabular}

2. Color de piel. La tabla 7 evidencia que solo se perfila esta característica para caracterizar entidades de tez clara. Las mujeres usan más este tipo de propiedades. La estructura SER + FADJ alcanza el $57.14 \%$ y SER + FPREP con la preposición de constituye el $42.8 \%$ del total. 
Los estados atributivos y locativos: estudio semántico cognitivo de la caracterización... Verónica Lazo García

Tabla 7. Frecuencia de uso de estructuras semántico-sintácticas de propiedades relacionadas con el color de piel

\begin{tabular}{c|l|l|l|l|l}
\hline Imagen & $\begin{array}{l}\text { Estructura } \\
\text { sintáctica }\end{array}$ & Formalización & Mujeres & Varones & Total \\
\hline \multirow{2}{*}{1} & SER + FADJ & $\sum$ (mujer, blanca) & 1 & 0 & 1 \\
\cline { 2 - 7 } & SER + FADJ & $\sum$ (mujer, caucásica) & 0 & 1 & 1 \\
\cline { 2 - 7 } & $\begin{array}{c}\text { SER + FPREP } \\
\text { (de) }\end{array}$ & $\begin{array}{l}\sum \text { de }(\text { mujer, tez/ piel } \\
\text { clara) }\end{array}$ & 2 & 0 & 2 \\
\hline 2 & SER+FADJ & $\sum$ (mujer, asiática) & 1 & 0 & 1 \\
\hline \multirow{2}{*}{5} & SER+FADJ & $\sum$ (niña, blanca) & 1 & 0 & 1 \\
\hline SER + FPREP & $\sum$ en (tez blanca, niña) & 1 & 0 & 1 \\
\hline Total & (de) & & 6 & 1 & 7 \\
\hline
\end{tabular}

3. El color, forma o tamaño del cabello. Las mujeres caracterizan a las entidades considerando esta atribución. Las estructuras SER + FPREP (de) y SER + FADJ alcanzan cada una el $41.66 \%$, y aparece el verbo TENER +FN, representando el $16.6 \%$ del total. La tabla 8 organiza lo mencionado.

Tabla 8. Frecuencia de uso de estructuras semántico-sintácticas de propiedades relacionadas con el color y la forma del cabello

\begin{tabular}{|c|c|c|c|c|c|}
\hline Imagen & $\begin{array}{l}\text { Estructura } \\
\text { sintáctica }\end{array}$ & Formalización & Mujeres & Varones & Total \\
\hline \multirow{2}{*}{1} & TENER + FN & $\begin{array}{l}\sum^{\text {en }} \text { (pelo castaño, } \\
\text { mujer) }\end{array}$ & 1 & 0 & 1 \\
\hline & $\begin{array}{l}\text { SER + FPREP } \\
(\mathrm{DE})\end{array}$ & $\begin{array}{l}\sum \text { en (cabello corto y } \\
\text { ondulado, mujer) }\end{array}$ & 2 & 0 & 2 \\
\hline 3 & $\begin{array}{l}\text { SER + FPREP } \\
(\mathrm{de})\end{array}$ & $\begin{array}{l}\sum^{\text {en }} \text { (cabello largo, } \\
\text { mujer) }\end{array}$ & 1 & 0 & 1 \\
\hline 4 & SER+FADJ & $\sum$ (niña, pelirroja) & 2 & 0 & 2 \\
\hline \multirow{3}{*}{5} & $\begin{array}{l}\text { SER + F PREP } \\
(\mathrm{de})\end{array}$ & $\begin{array}{l}\sum^{\text {en }} \text { (pelo rubio/ } \\
\text { cabello castaño, niña) }\end{array}$ & 2 & 0 & 2 \\
\hline & TENER + FN & $\begin{array}{l}\sum^{\text {en }} \text { (cabello castaño, } \\
\text { niña) }\end{array}$ & 1 & 0 & 1 \\
\hline & SER+FADJ & $\sum$ (niña, rubia) & 2 & 1 & 3 \\
\hline \multicolumn{3}{|l|}{ Total } & 11 & 1 & 12 \\
\hline
\end{tabular}

$98 \quad$ Lengua y Sociedad. Revista de Lingüística Teórica y Aplicada 
Los estados atributivos y locativos: estudio semántico cognitivo de la caracterización...

Verónica Lazo García

4. Sobre el tamaño, solo en la imagen 5 , se emplea la frase adjetiva pequeña para referirse a la niña. Las mujeres son las únicas que lo usan.

\section{B. La edad}

La atribución de la edad de la entidad es menos frecuente. De acuerdo con la tabla 9, cuando la entidad es un niño, como en las imágenes 4 y 5 , su frecuencia es bajísima. Las mujeres perfilan o prestan más atención a las propiedades dentro de este dominio. La estructura más frecuente es SER + FADJ, con un $66.6 \%$. Las otras estructuras SOn SER + FPREP (de, entre) y VERSE + FADJ.

Tabla 9. Frecuencia de uso de estructuras semántico-sintácticas de propiedades relacionadas con la edad

\begin{tabular}{c|l|l|l|l|l}
\hline Imagen & $\begin{array}{l}\text { Estructura } \\
\text { sintáctica }\end{array}$ & Formalización & Mujeres & Varones & Total \\
\hline \multirow{2}{*}{1} & SER + FADJ & $\sum$ (mujer, joven) & 1 & 1 & 2 \\
\cline { 2 - 6 } & $\begin{array}{l}\text { SER + FPREP } \\
(\mathrm{de})\end{array}$ & $\sum$ (mujer, 30 años) & 1 & 0 & 1 \\
\hline \multirow{2}{*}{2} & SER + FADJ & $\sum$ (mujer, joven) & 2 & 0 & 2 \\
\cline { 2 - 6 } & Verse + FADJ & $\sum$ (mujer, madura) & 1 & 0 & 1 \\
\hline \multirow{2}{*}{3} & SER+FADJ & $\sum$ (mujer, joven) & 3 & 1 & 4 \\
\cline { 2 - 6 } & $\begin{array}{l}\text { SER + FPREP } \\
(\text { de })\end{array}$ & $\sum$ (mujer, 21 años) & 1 & 0 & 1 \\
\hline 5 & $\begin{array}{l}\text { SER + FPREP } \\
(\text { (entre })\end{array}$ & $\sum$ (niña, 3 a 5 años) & 1 & 0 & 1 \\
\hline \multirow{2}{*}{ TOTAL } & & & 10 & 2 & 12 \\
\hline
\end{tabular}

\section{La imagen}

A diferencia de la edad y el físico, la imagen contiene propiedades permanentes y transitorias con el verbo ser y estar. La estructura sintáctica ESTAR + FADJ alcanza el $37.03 \%$ de las atribuciones; mientras que las estructuras SER + FADJ y TENER + FN representan cada una el $\mathbf{2 2 . 2} \%$. Se aprecia el uso de otras estructuras con menor frecuencia: ANDAR + FADJ, IR + FADJ Y VERSE + FADJ (todas con $3.7 \%$ ). Hay una atribución inherente en es una niña de gran sonrisa. Las mujeres usan más expresiones de esta propiedad, como se indica en la tabla 10. 
Los estados atributivos y locativos: estudio semántico cognitivo de la caracterización... Verónica Lazo García

Tabla 10. Frecuencia de uso de estructuras semántico-sintácticas de propiedades relacionadas con la imagen

\begin{tabular}{|c|c|c|c|c|c|}
\hline Imagen & $\begin{array}{l}\text { Estructura } \\
\text { sintáctica }\end{array}$ & Formalización & Mujeres & Varones & Total \\
\hline \multirow{2}{*}{1} & $\begin{array}{l}\text { ESTAR + FADJ } \\
\text { (participio) }\end{array}$ & $\begin{array}{l}\sum \text { (mujer, vestida con } \\
\text { ropa deportiva) }\end{array}$ & 0 & 1 & 1 \\
\hline & $\begin{array}{l}\text { ANDAR + FADJ } \\
\text { (participio) }\end{array}$ & $\begin{array}{l}\sum \text { (mujer, vestida de } \\
\text { azul) }\end{array}$ & 1 & 0 & 1 \\
\hline \multirow{6}{*}{2} & SER+FADJ & $\sum$ (mujer, atlética) & 1 & 1 & 2 \\
\hline & SER+FN & $\sum$ (mujer, deportista) & 0 & 3 & 3 \\
\hline & $\begin{array}{l}\text { VERSE + FADJ } \\
\text { Resultado }\end{array}$ & $\sum$ (mujer, cansada) & 1 & 0 & 1 \\
\hline & SER + FADJ & $\sum$ (mujer, vestida) & 1 & 0 & 1 \\
\hline & TENER + FN & $\sum^{\mathrm{IN}}$ (moño, cabeza) & 1 & 0 & 1 \\
\hline & TENER + FN & $\begin{array}{l}\sum \text { recogido (mujer, } \\
\text { cabello) }\end{array}$ & 2 & 0 & 2 \\
\hline \multirow{2}{*}{3} & $\begin{array}{l}\text { ESTAR+FADJ } \\
\text { participio }\end{array}$ & $\begin{array}{l}\sum \text { (mujer, arreglada/ } \\
\text { vestida) }\end{array}$ & 2 & 0 & 2 \\
\hline & SER + FN & $\begin{array}{l}\sum \text { (mujer, estudiante } \\
\text { universitaria) }\end{array}$ & 1 & 0 & 1 \\
\hline \multirow[b]{2}{*}{4} & $\begin{array}{l}\text { IR + FADJ } \\
\text { (PARTICIPIO) }\end{array}$ & $\begin{array}{l}\sum \text { (niña, vestida de } \\
\text { camisa roja) }\end{array}$ & 1 & 0 & 1 \\
\hline & $\begin{array}{l}\text { SER + FPREP } \\
(\text { de) } \\
\text { Cualidad } \\
\end{array}$ & $\begin{array}{l}\sum^{\text {en }}(\text { gran sonrisa, } \\
\text { niña) }\end{array}$ & 1 & 0 & 1 \\
\hline \multirow[t]{2}{*}{5} & $\begin{array}{l}\text { ESTAR + FADJ } \\
\text { (PARTICIPIO) }\end{array}$ & $\begin{array}{l}\sum^{\mathrm{VESTIDA} \text {, PEINADA }} \text { (niña, } \\
\text { de/con polo morado, } \\
\text { con dos colitas) }\end{array}$ & 5 & 2 & 7 \\
\hline & TENER + FN & $\begin{array}{l}\sum \text { amarrado, desordenado, recogido } \\
\text { (cabello, niña) }\end{array}$ & 3 & 0 & 3 \\
\hline \multicolumn{3}{|l|}{ Total } & 20 & 7 & 27 \\
\hline
\end{tabular}

D. La evaluación de la belleza

La evaluación de la belleza se produce únicamente en relación con la imagen 1. A diferencia de las imágenes donde aparecen dibujos de mujeres adultas, está es una fotografía, por tanto, se ve más real. Las imágenes de los niños tanto como 
Los estados atributivos y locativos: estudio semántico cognitivo de la caracterización...

Verónica Lazo García

fotografía y como dibujo no presentan esta atribución. La única estructura sintáctica es SER + FADJ, como consta en la tabla 11.

Tabla 11. Frecuencia de uso de estructuras semántico-sintácticas de propiedades relacionadas con la belleza

\begin{tabular}{|l|l|l|l|l|}
\hline \multirow{2}{*}{ EST SINT } & Adjetivo & Mujeres & Varones & Total \\
\hline \multirow{3}{*}{ SER + FAJ } & $\sum$ (mujer, guapa) & 1 & 1 & 2 \\
\cline { 2 - 5 } & $\sum$ (mujer, bella $)$ & 0 & 1 & 1 \\
\cline { 2 - 5 } & $\sum$ (mujer, bonita) & 1 & 0 & 1 \\
\hline \multirow{3}{*}{} & Total & 2 & 2 & 4 \\
\cline { 2 - 5 }
\end{tabular}

\subsection{El dominio postura-Iugar}

Este dominio abarca tanto la descripción de la postura de la entidad como su ubicación respecto de otra entidad (lugar). En la descripción de las imágenes 3 y 4 los colaboradores perfilan rasgos de este dominio para caracterizar las entidades. Con respecto a la postura, se emplea la estructura ESTAR + PARTICIPIO. Según la tabla 12, los varones usan un poco más que las mujeres este tipo de atribuciones (6o \% frente a $40 \%)$.

Tabla 12. Frecuencia de uso de estructuras semántico-sintácticas de propiedades relacionadas con la postura

\begin{tabular}{c|l|l|l|l|l}
\hline Imagen & $\begin{array}{l}\text { Estructura } \\
\text { sintáctica }\end{array}$ & Formalización & Mujeres & Varones & Total \\
\hline 3 & $\begin{array}{l}\text { ESTAR+FADJ } \\
\text { participio }\end{array}$ & $\begin{array}{l}\sum \text { (mujer, echada/ } \\
\text { recostada) }\end{array}$ & 3 & 4 & 7 \\
\hline 4 & $\begin{array}{l}\text { ESTAR+FADJ } \\
\text { participio }\end{array}$ & $\begin{array}{l}\sum \text { (niño, acostado/ } \\
\text { parado/ echado) }\end{array}$ & 1 & 2 & 3 \\
\hline Total & & 4 & 6 & 10 \\
\hline
\end{tabular}

La localización de las entidades solo se especifica en la descripción de las imágenes 4 y 5. La estructura sintáctica más frecuente es SER + FPREP (de), con $61.9 \%$. Le sigue la construcción relativa con estado locativo inesivo o superesivo QUE+ ESTAR (EN/ SOBRE), con $33.3 \%$. Finalmente, de acuerdo con la tabla 13, las mujeres usan más este tipo de estados. 
Los estados atributivos y locativos: estudio semántico cognitivo de la caracterización... Verónica Lazo García

Tabla 13. Frecuencia de uso de estructuras semántico-sintácticas de propiedades relacionadas con la localización

\begin{tabular}{|c|c|c|c|c|c|}
\hline Imagen & $\begin{array}{l}\text { Estructura } \\
\text { sintáctica }\end{array}$ & Formalización & Mujeres & Varones & Total \\
\hline \multirow{3}{*}{4} & $\begin{array}{l}\text { SER + Fprep } \\
(\mathrm{de})\end{array}$ & $\begin{array}{l}\sum^{\text {en }} \text { (niño, columpio/ } \\
\text { trampolín/ esquina) }\end{array}$ & 6 & 6 & 12 \\
\hline & $\begin{array}{l}\text { ESTAR + Fprep } \\
\text { (en) }\end{array}$ & $\begin{array}{l}\sum^{\text {en }}(\text { niño, cama } \\
\text { saltarina) }\end{array}$ & 1 & 0 & 1 \\
\hline & $\begin{array}{l}\text { QUE + estado } \\
\text { locativo }\end{array}$ & $\begin{array}{l}<\mathrm{SA}, \sum\left({ }^{\mathrm{niño}}\right], \sum^{\mathrm{en} / \mathrm{sobre}} \\
[\mathrm{FN}])>\end{array}$ & 6 & 1 & 7 \\
\hline 5 & $\begin{array}{l}\text { SER + Fprep } \\
(\mathrm{de})\end{array}$ & $\sum^{\text {en }}$ (niño, izquierda) & 0 & 1 & 1 \\
\hline \multicolumn{3}{|l|}{ Total } & 13 & 8 & 21 \\
\hline
\end{tabular}

\subsection{El dominio de la actitud}

La actitud es expresada por adjetivos relacionados con las relaciones sociales, como la felicidad, la tenacidad, el cansancio o la agresividad. Las mujeres emplean más atribuciones dentro de este dominio que los varones. La estructura más frecuente es SER + FADJ, con $58.9 \%$, seguida de ESTAR + FADJ, con $25.6 \%$ (ver tabla 14). Se aprecia otras estructuras con verbos encontrarse, parecer, verse, tener.

Tabla 14. Frecuencia de uso de estructuras semántico-sintácticas de propiedades relacionadas con la actitud

\begin{tabular}{|c|l|l|l|l|l|}
\hline Imagen & $\begin{array}{l}\text { Estructura } \\
\text { sintáctica }\end{array}$ & Formalización & Mujeres & Varones & Total \\
\hline & SER+ FADJ & $\begin{array}{l}\sum \text { (mujer, feliz, } \\
\text { sonriente, alegre) }\end{array}$ & 5 & 1 & 6 \\
\cline { 2 - 6 } 1 & $\begin{array}{l}\text { ENCONTRARSE }+ \\
\text { FADJ }\end{array}$ & $\sum$ (mujer, feliz, $)$ & 0 & 1 & 1 \\
\cline { 2 - 6 } & $\begin{array}{l}\text { SER/ POSAR }+ \\
\text { FADJ }\end{array}$ & $\sum$ (mujer, sensual) & 2 & 0 & 2 \\
\hline
\end{tabular}


Los estados atributivos y locativos: estudio semántico cognitivo de la caracterización...

Verónica Lazo García

\begin{tabular}{|c|c|c|c|c|c|}
\hline Imagen & $\begin{array}{l}\text { Estructura } \\
\text { sintáctica }\end{array}$ & Formalización & Mujeres & Varones & Total \\
\hline \multirow{7}{*}{2} & SER+FADJ & $\begin{array}{l}\sum \text { (mujer, alegre, } \\
\text { feliz, sonriente) }\end{array}$ & 4 & 0 & 4 \\
\hline & ESTAR+FADJ & $\begin{array}{l}\sum \text { (mujer, alegre, } \\
\text { feliz) }\end{array}$ & 1 & 1 & 2 \\
\hline & PARECER + FADJ & $\sum$ (mujer, feliz) & 0 & 1 & 1 \\
\hline & VERSE + FADJ & $\sum$ (mujer, contenta) & 1 & 0 & 1 \\
\hline & $\begin{array}{l}\text { SER + FPREP } \\
(\mathrm{DE})\end{array}$ & $\begin{array}{l}\sum \text { (mujer, semblante } \\
\text { alegre) }\end{array}$ & 1 & 0 & 1 \\
\hline & SER + FADJ & $\begin{array}{l}\sum \text { (mujer, } \\
\text { luchadora) }\end{array}$ & 0 & 1 & 1 \\
\hline & $\begin{array}{l}\text { SER + FADJ } \\
\text { (participio) }\end{array}$ & $\sum$ (mujer, decidida) & 1 & 1 & 2 \\
\hline \multirow{3}{*}{3} & $\begin{array}{l}\text { ESTAR + FADJ } \\
\text { Participio }\end{array}$ & $\begin{array}{l}\sum \text { (mujer, relajada/ } \\
\text { despreocupada) }\end{array}$ & 4 & 4 & 8 \\
\hline & SER + FADJ & $\begin{array}{l}\sum \text { (mujer, floja/ } \\
\text { aburrida) }\end{array}$ & 1 & 0 & 1 \\
\hline & SER + FADJ & $\begin{array}{l}\sum \text { (mujer, } \\
\text { extrovertida/ } \\
\text { amigable) }\end{array}$ & 1 & 0 & 1 \\
\hline \multirow{3}{*}{5} & SER + FADJ & $\begin{array}{l}\sum \text { (niña, agresiva, } \\
\text { ruidosa, irritante/ } \\
\text { molesta, colérica, } \\
\text { graciosa, gritona) }\end{array}$ & 3 & 2 & 5 \\
\hline & SER + FADJ & $\begin{array}{l}\sum \text { (niño, sensible/ } \\
\text { pacífico, } \\
\text { desesperado) }\end{array}$ & 1 & 1 & 2 \\
\hline & TENER + FN & $\begin{array}{l}\sum^{\mathrm{eN}}(\text { ceño fruncido, } \\
\text { niña) }\end{array}$ & 1 & 0 & 1 \\
\hline \multicolumn{3}{|l|}{ Total } & 26 & 13 & 39 \\
\hline
\end{tabular}

\subsection{El dominio de las acciones}

Casi todos los predicados de la construcción relativa tienen el antecedente como agente que se expresa sintácticamente como sujeto. De acuerdo con la frecuencia mostrada en la tabla 15, este es el único dominio en que predomina el uso de atribuciones por los varones. 
Los estados atributivos y locativos: estudio semántico cognitivo de la caracterización... Verónica Lazo García

Tabla 15. Frecuencia de uso de estructuras semántico-sintácticas de propiedades relacionadas con el rol en sucesos

\begin{tabular}{|c|c|c|c|c|c|}
\hline Imagen & $\begin{array}{l}\text { Estructura } \\
\text { sintàctica }\end{array}$ & Formalización & Mujeres & Varones & Total \\
\hline \multirow{3}{*}{2} & $\begin{array}{l}\text { QUE + VESTIR } \\
\text { ROPA }\end{array}$ & $\begin{array}{l}<\mathrm{SA}, \sum([\text { mujer }], \text { viste } \\
\text { ropa deportiva } \\
\left.\left[{ }^{\text {mujer }}\right]\right)>\end{array}$ & 1 & 0 & 1 \\
\hline & $\begin{array}{l}\text { QUE+ } \\
\text { PONERSE EN } \\
\text { FORMA }\end{array}$ & $\begin{array}{l}<\mathrm{SA}, \sum\left(\left[{ }^{\mathrm{mujer}}\right]\right. \\
\text { ponerse en forma } \\
\left.\left[{ }^{\text {mujer }}\right]\right)>\end{array}$ & 0 & 1 & 1 \\
\hline & $\begin{array}{l}\text { QUE }+ \\
\text { EJERCITARSE }\end{array}$ & $\begin{array}{l}<\text { SA, } \sum\left(\left[{ }^{\text {mujer }}\right], \text { está }\right. \\
\left.\text { ejercitando }\left[{ }^{\text {mujer }}\right]\right)>\end{array}$ & 0 & 1 & 1 \\
\hline \multirow{4}{*}{3} & QUE + LLEVAR & $\begin{array}{l}<\text { SA, } \sum([\text { mujer }], \text { lleva } \\
\text { estilo de vestir } \\
{\left[{ }^{\text {mujer }]}\right)>}\end{array}$ & 0 & 1 & 1 \\
\hline & $\begin{array}{l}\text { QUE+ TOMA } \\
\text { UN MOMENTO } \\
\text { PARA } \\
\text { DESCANSAR }\end{array}$ & $\begin{array}{l}<\mathrm{SA}, \sum([\text { mujer }] \\
\text { toma un momento } \\
\left.\left[{ }^{\text {mujer }}\right]\right)>\end{array}$ & 1 & 0 & 1 \\
\hline & $\begin{array}{l}\text { QUE }+ \\
\text { DESCANSAR }\end{array}$ & $\begin{array}{l}<\mathrm{SA}, \sum([\text { mujer }], \\
\left.\text { descansa }\left[{ }^{\text {mujer }}\right]\right)>\end{array}$ & 0 & 1 & 1 \\
\hline & $\begin{array}{l}\text { QUE + MIRAR } \\
\text { TV }\end{array}$ & $\begin{array}{l}<\text { SA, } \sum([\text { mujer }], \text { mira } \\
\text { TV [mujer }])>\end{array}$ & 0 & 1 & 1 \\
\hline \multirow{5}{*}{4} & QUE + CORRER & $\begin{array}{l}<\mathrm{SA}, \sum\left(\left[{ }^{\text {niña }}\right], \text { corre }\right. \\
\left.\left[{ }^{\text {niña }}\right]\right)>\end{array}$ & 1 & 0 & 1 \\
\hline & $\begin{array}{l}\text { QUE+ TENER } \\
\text { LA FLOR }\end{array}$ & $\begin{array}{l}<\mathrm{SA}, \sum([\text { niña }], \text { tiene } \\
\text { la flor [niña }])>\end{array}$ & 1 & 0 & 1 \\
\hline & QUE + SALTAR & $\begin{array}{l}<\mathrm{SA}, \sum\left(\left[{ }^{\text {niño }}\right], \text { salta }\right. \\
\left.\left[{ }^{\text {niño }}\right]\right)>\end{array}$ & 0 & 2 & 2 \\
\hline & QUE + JUGAR & $\begin{array}{l}<\mathrm{SA}, \sum\left(\left[{ }^{\text {niño }}\right], \text { juega }\right. \\
\left.\left[{ }^{\text {niño }}\right]\right)>\end{array}$ & 0 & 1 & 1 \\
\hline & Que +HABLAR & $\begin{array}{l}<\mathrm{SA}, \sum\left(\left[{ }^{\text {niño }}\right], \text { habla }\right. \\
\left.\left[{ }^{\text {niño }}\right]\right)>\end{array}$ & 0 & 1 & 1 \\
\hline \multirow{2}{*}{5} & QUE + ESTAR & $\begin{array}{l}<\mathrm{SA}, \sum\left(\left[{ }^{\text {niña }}\right], \sum^{\text {con }}\right. \\
\left.\left[{ }^{\text {niña }}\right]\right)>\end{array}$ & 1 & 0 & 1 \\
\hline & $\begin{array}{l}\text { Al QUE+ } \\
\text { FASTIDIAR }\end{array}$ & $\begin{array}{l}<\mathrm{sA}, \sum\left(\left[{ }^{\text {niño }}\right]\right. \\
\left.\left.\text { fastidia [ }{ }^{\text {niño }}\right]\right)>\end{array}$ & 0 & 1 & 1 \\
\hline \multicolumn{3}{|l|}{ Total } & 5 & 10 & 15 \\
\hline
\end{tabular}


Los estados atributivos y locativos: estudio semántico cognitivo de la caracterización...

Verónica Lazo García

Los verbos que caracterizan a las entidades varían de acuerdo con la imagen. La imagen 4 (véase Figura 2) genera más construcciones relativas. Los niños de la figura son caracterizados como agentes de los verbos correr, saltar, hablar, jugar e, incluso, el verbo tener, que expresa un atributo. Las entidades perfilan el rol de agente, la cual por su alto grado de caracterización es la menos marcada. Se aprecia una caracterización de la entidad a partir del rol del experimentante en la construcción Un niño (al) que le fastidia(n) bastante los gritos de la niña, que es una ventana atencional de la figura 3 (imagen 5 del cuestionario).

Figura 2. Imagen 4 del cuestionario

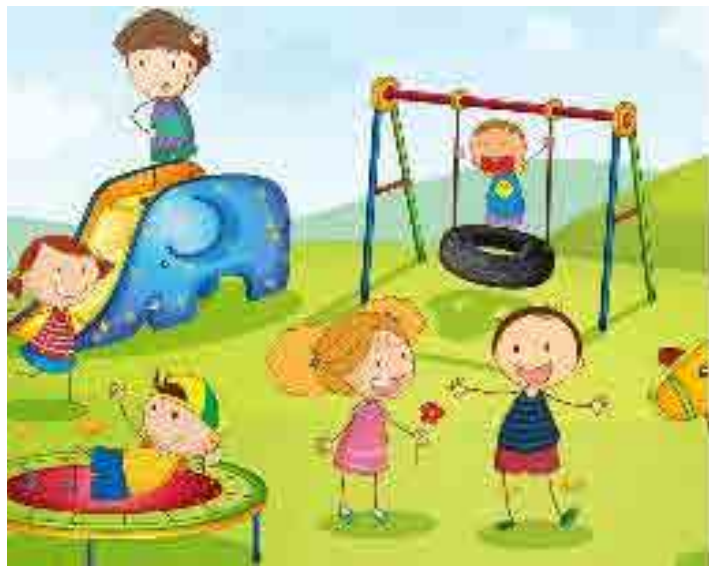

Figura 3. Imagen 5 del cuestionario

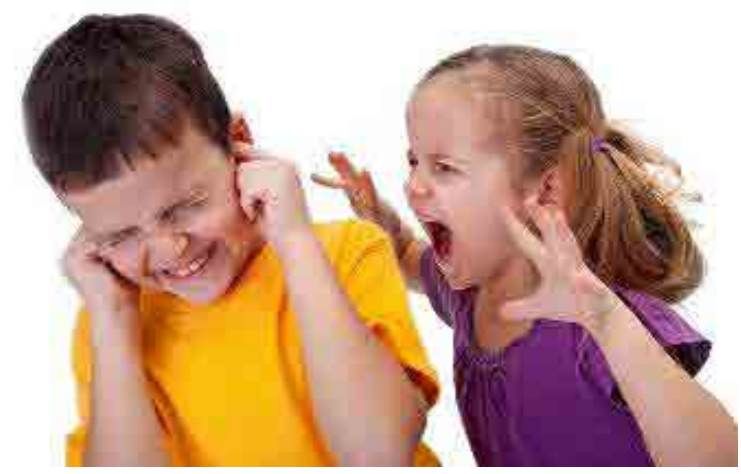

Sobre el continuum de caracterización propuesto por Moreno (1998), se observa que de acuerdo con el dominio conceptual se perfilan propiedades y se expresan en diversas estructuras sintácticas: 
Los estados atributivos y locativos: estudio semántico cognitivo de la caracterización... Verónica Lazo García

\begin{tabular}{lllll} 
Sustantivos & adjetivos & F prep & participios & subordinadas relativas \\
\hline \multirow{3}{*}{ imagen } & $\begin{array}{l}\text { contextura } \\
\text { belleza }\end{array}$ & lugar & $\begin{array}{l}\text { postura } \\
\text { imagen }\end{array}$ & Lugar \\
& edad & & & \\
& cabello & cabello & & \\
piel & & \\
& actitud & &
\end{tabular}

Cuando las propiedades identifican al individuo por su imagen, se emplean sustantivos. Las atribuciones emplean más frases adjetivas, vinculadas a lo físico, como la contextura, belleza, edad, cabello y piel, y también con la actitud. Las frases preposicionales se usan para caracterizar a la entidad por su localización y la forma o color de su cabello. Los participios expresan propiedades relacionadas con la postura de la entidad y su imagen. Finalmente, las construcciones relativas se emplean para caracterizar a la entidad por su estado locativo.

Sobre la variable género

Como se ha podido verificar de la información de las tablas, las mujeres prestan más atención a propiedades físicas como el color de piel, color y forma del cabello, edad y actitud. Ahora bien, que las mujeres perfilen estas propiedades (perfilamiento de Langacker o ventana atencional de Talmy) se basa en que ellas usan más descriptores que los varones, es decir, su red semántica del color es más amplia (Rivera, 2001), porque son educadas para tener mayor cuidado en la imagen que proyectan. Sin embargo, consideramos que esta variable no es estática y se relaciona con otras, como el nivel de estudio, el objeto que se caracterice y la situación. Además, como se resume en la tabla 16, las mujeres construyeron atribuciones complejas, de hasta 6 propiedades. Los varones solo caracterizaron a las entidades máximo con dos propiedades.

106 Lengua y Sociedad. Revista de Lingüística Teórica y Aplicada 
Los estados atributivos y locativos: estudio semántico cognitivo de la caracterización...

Verónica Lazo García

Tabla 16. Frecuencia de uso de número de propiedades por género

\begin{tabular}{|l|l|l|l|}
\hline $\begin{array}{l}\text { Número de } \\
\text { propiedades }\end{array}$ & Mujeres & Varones & Total \\
\hline 1 & 33 & 41 & 74 \\
\hline 2 & 20 & 11 & 31 \\
\hline 3 & 7 & 1 & 8 \\
\hline 4 & 2 & 0 & 2 \\
\hline 5 & 1 & 0 & 1 \\
\hline 6 & 2 & 0 & 2 \\
\hline TOTAL & 65 & 53 & 118 \\
\hline
\end{tabular}

Una de las cuestiones más debatidas en la sociolingüística es si las diferencias lingüísticas entre hombres y mujeres se deben a su propia naturaleza biológica o son aprendidas culturalmente desde la infancia (Serrano, 2008). Para ello se argumenta que «las mujeres desarrollan aptitudes para el habla, la música y el dibujo por sus características neurológicas asociadas con su hemisferio cerebral dominante es el izquierdo, que es el responsable del desarrollo de esas habilidades» (Lozano, 1995, p. 219).

Según Lakoff (1975, citada por Serrano, p. 180) la gama de colores, ciertos adjetivos calificativos, como lindo o dulce expresados en el habla femenina, no aparecen en el habla masculina. En respuesta a este trabajo, Lozano (1995) señala que es impresionista. Los estudios relacionados con la variable sexo o género consideran el conservadurismo, es estatus y la solidaridad. Se ha mencionado que las mujeres emplean formas más prestigiosas para obtener cierto nivel social.

\section{Conclusiones}

1. La atribución permanente es la más frecuente y presenta más diversidad en la estructura sintáctica. Se emplearon los verbos ser y tener; con frases adjetivas, frases preposicionales. En la atribución transitoria, aparece el verbo estar acompañado por participios (resultados) y frases adjetivas. En la caracterización también se aprecia el juicio u opinión del hablante, con el uso de verbos semicopulativos, donde destaca el verbo pronominal verse. 
Los estados atributivos y locativos: estudio semántico cognitivo de la caracterización... Verónica Lazo García

2. Desde el punto de vista cognitivo, la propiedad de contextura solo se atribuye a personas adultas; el color de piel y de cabello, tamaño, edad, imagen, belleza, solo se atribuyen a mujeres o niñas, del mismo modo, las mujeres usan esta atribución con más frecuencia. La tabla 5 muestra la ventana de atención o perfilamiento de la caracterización, es decir, según la forma como perciben la entidad, hombres y mujeres les atribuyen distintas propiedades en distinto grado. En las imágenes 1, 2 y 3 hay mujeres, pero solo en la imagen 1 destacan su físico, en 2 y 3 su actitud. En las figuras 4 y 5 las imágenes corresponden a niños, pero en 4 perfilan el lugar y en 5 , la imagen que proyectan.

3. El dominio cognitivo concreto visual presentó mayor riqueza semántica, puesto que se refiere a la contextura, color de piel, de cabello, edad, ropa, imagen y evaluación de la belleza. Respecto de la contextura, su estructura sintáctica es SER + FADJ y los niños no son caracterizados con este rasgo; sobre el color de piel solo se atiende cuando es de tez clara y la estructura sintáctica SER +FADJ alterna con SER + FPREP. La forma del cabello solo es atendida por las mujeres, quienes construyen estructuras de tipo SER + FPREP, SER + FADJ Y TENER + FN. La edad también es un atributo considerado mayoritariamente por las mujeres, y se expresa con las estructuras SER + FADJ, SER + FPREP y VERSE+FADJ. La imagen, igual que la forma del cabello y la edad, es un rasgo importante en la caracterización por parte de las mujeres; se expresa en la sintaxis con estructuras ESTAR + FADJ, SER + FADJ, TENER + FN. Finalmente, la belleza solo se ha empleado para caracterizar a la figura 1, con la estructura SER + FADJ.

4. El dominio postura-lugar presenta diferentes frecuencias de uso. Así, los varones emplean un poco más atributos de postura, con la estructura sintáctica ESTAR + PARTICIPIO, para las imágenes 3 y 4 . En cambio, las mujeres emplean más los atributos de localización, con la estructura SER + FPREP (de). Por su parte, la actitud perfila marcos o dominios relacionados con relaciones sociales. Las mujeres emplean más este tipo de propiedades. La estructura sintáctica más frecuencia es SER + FADJ. Finalmente, cuando caracterizan a la entidad por su papel en un evento, destacan su rol de agente. En este tipo de atribución, los varones emplean más propiedades. 
Los estados atributivos y locativos: estudio semántico cognitivo de la caracterización...

Verónica Lazo García

5. Existe una relación entre semántica y sintaxis. El uso de atributos de dominio cognitivo concreto visual corresponde a frases adjetivas; la localización, a frases preposicionales; la postura y la imagen, a participios; el rol en el evento, a construcciones relativas.

6. Las mujeres y los varones conceptualizan de manera diferente las entidades representadas en las imágenes del cuestionario. Así, las mujeres caracterizan a las entidades con más atributos que los varones: se aprecia 32 atribuciones complejas elaboradas por las mujeres frente a 12 de los varones. Ellas emplean propiedades referidas al color de piel, la edad, la imagen y la actitud. Los varones, en cambio, realizan la caracterización a partir de la acción que realiza la entidad. Es posible que en el modelo sociocultural femenino las entidades se perciban con ciertas propiedades, como la forma, el color, la edad y la actitud.

\section{Agradecimientos}

Agradezco los alcances brindados por la lingüista Yolanda Julca Estrada, profesora del curso de Lingüística General en la Universidad Federico Villarreal. También es oportuno señalar un agradecimiento a Marco Lovón Cueva por sus observaciones y revisiones para la confección del presente manuscrito.

\section{Financiamiento}

La investigación se realizó sin financiamiento. Este artículo se deriva del proyecto de investigación sin financiamiento titulado La subordinación relativa en los textos escritos de los alumnos de la Facultad de Letras y Ciencias Humanas de la UNMSM, con código E17030122, RR 06343-R-17.

\section{Conflicto de intereses}

La autora no presenta conflicto de interés. 
Los estados atributivos y locativos: estudio semántico cognitivo de la caracterización... Verónica Lazo García

\section{Referencias bibliográficas}

Chafe, W. (1970). Meaning and the structure of language. University of Chicago. Demonte, V. (1979). Semántica y sintaxis de las construcciones con 'ser' y 'estar'. Revista española de lingüistica, 9(1), 133-172. http://www.sel.edu.es/pdf/ ene-jun-79/demonte\%2079.pdf

Fillmore, Ch. (1985). Frames and the semantics of understanding, Quaderni di Semantica, 6, 222-254. http://www.icsi.berkeley.edu/pubs/ai/framesand85.pdf

Maldondado, R. (2012). Gramática cognitiva. En Ibarretxe-Antuñano, I., y Valenzuela, J. (Eds.) Lingüística cognitiva (pp. 213-247). Anthropos.

Katz, J., \& Fodor, J. (1963). The structure of a semantic theory. Language, 39, 170-210. https://bit.ly/3vzsFFi

Langacker, R. (1999). Grammar and conceptualization. Mouton de Gruyter.

Leech, G. (1977). Semántica. Alianza Editorial.

Lyons, J. (1997). Semántica lingüística. Una introducción. Editorial Paidós.

Moreno Cabrera, J. (1998). Sintaxis formal y sintaxis conceptual: más allá de la tipología de las oraciones de relativo. Syntaxis 1, 63-92. http://rabida.uhu.es/ dspace/handle/10272/3194

Moreno Cabrera, J. (2003). Semántica y gramática: sucesos, papeles semánticos y relaciones sintácticas. A. Machado Libros S. A.

Montague, R. (1974). Gramática Universal. En R. Montague Ensayos de Filosofía Formal (pp. 158-182). Alianza Editorial

Otaola Olano, C. (2004). Lexicología y semántica léxica. Teoría y aplicación a la lengua española. Ediciones Académicas.

Real Academia Española. (2010). Nueva gramática de la lengua española. Manual. Espasa Libros.

Rivera, M. E. (2001). Percepción y significado del color en diferentes grupos sociales. Inv. Univ. Mult, 3, 74-83. https://dialnet.unirioja.es/descarga/articulo/3684094.pdf

Serrano, M. J. (2008). El rol de la variable sexo o género en sociolingüística: ¿diferencia, dominio o interacción? Boletín de Filología, XLIII, 175-192. https://ultimadecada.uchile.cl/index.php/BDF/article/view/18049

Talmy, L. (2000). Toward a cognitive semantics. Volume 1. Concept structuring systems. Massachusetts Institute of Technology.

110 Lengua y Sociedad. Revista de Lingüística Teórica y Aplicada 
Los estados atributivos y locativos: estudio semántico cognitivo de la caracterización...

Verónica Lazo García

\section{Anexo}

\section{Esquema del cuestionario}

\begin{tabular}{|c|c|c|}
\hline & Imagen & Pregunta \\
\hline \multirow{7}{*}{ 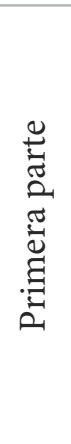 } & 1 & ¿Cómo es la mujer de la imagen? ¿Qué está haciendo? \\
\hline & 2 & $\begin{array}{l}\text { Mire la imagen, ¿cómo describe a la mujer? ¿Qué está } \\
\text { haciendo? }\end{array}$ \\
\hline & 3 & Luego de observar la imagen, ¿cómo caracterizaría a la mujer? \\
\hline & 4 & ¿Con qué niño(a) de la imagen te identificarías? ¿Por qué? \\
\hline & 5 & ¿Qué características tiene el(la) niño(a) de la imagen? \\
\hline & 6 & ¿Cómo describes la situación que se aprecia en la imagen? \\
\hline & 7 & ¿Cómo caracteriza la situación que se aprecia en la imagen? \\
\hline 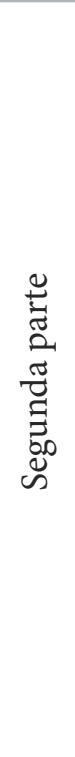 & $\begin{array}{c}\text { Completa las } \\
\text { siguientes } \\
\text { oraciones. }\end{array}$ & 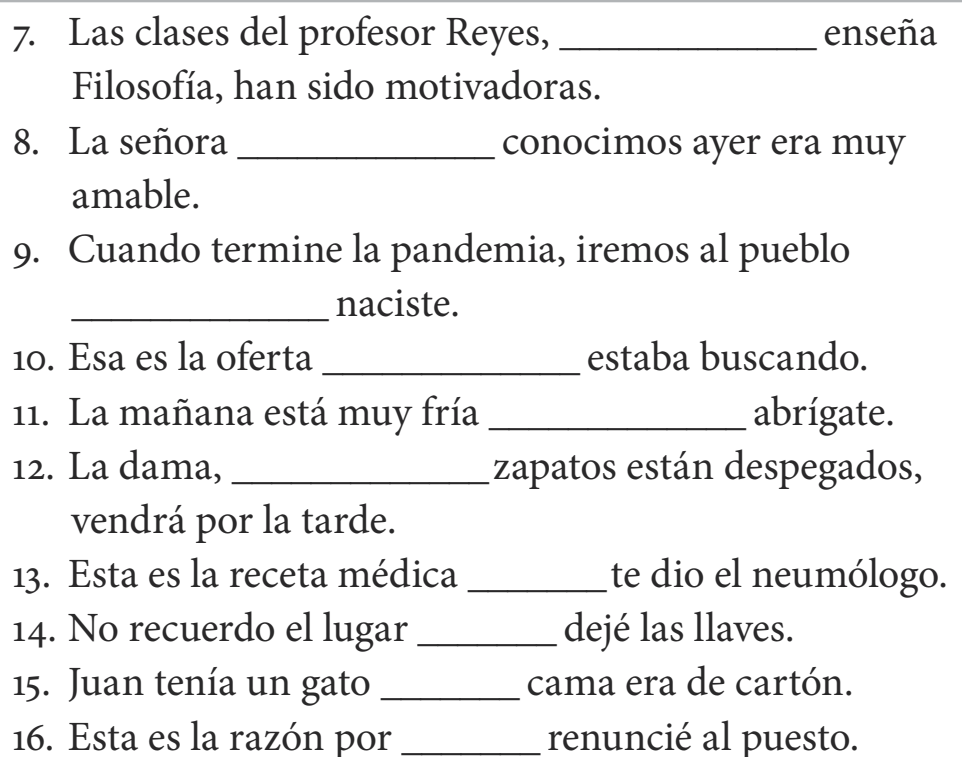 \\
\hline
\end{tabular}

\section{Trayectoria académica del autor}

Magíster en lingüística por la Universidad Nacional Mayor de San Marcos. Verónica Lazo es docente en la UNMSM y perito en lingüística. Tiene estudios concluidos de doctorado en Lingüística por la Universidad Nacional Mayor de San Marcos. Sus intereses de investigación se centran en la semántica, el análisis del discurso, la fonética y la lingüística forense. Cuenta con publicaciones sobre marcadores del discurso y sobre gramática cognitiva. 